\title{
Sınıf Öğretmeni Adaylarının Sürdürülebilir Kalkınma İçin Eğitim İle İlgili Görüşleri*
}

\section{Classroom Teacher Candidates' Views on Education for Sustainable Development}

\section{Mustafa UĞRAŞ}

\author{
Erdal ZENGİN
}

Received: 11 July 2018

Research Article

Accepted: 04 November 2018

ABSTRACT: The aim of the present study was to determine the views of classroom teacher candidates on education for sustainable development. In this research, phenomenology has been used as a qualitative research approach. For the purpose of this study, appropriate sampling was preferred from the purposeful sampling techniques. The study group included 30 classroom teacher candidates'. In the present study, data were gathered by interview technique. The semi-structured interview form developed by the researchers was used as data collection tool and the obtained data was described using the content analysis technique. It was determined that classroom teacher candidates had positive views on education for sustainable development in general. Teacher candidates stated that education for sustainable development should be given from the pre-school period. In addition, teacher candidates participating in the research have been stated to be the most effective method of out-of-school trips. Some of the remaining participants expressed that drama might be effective methods of watching related videos.

Keywords: classroom teacher candidates, education for sustainable development, environmental education.

ÖZ: Bu çalışma sınıf öğretmeni adaylarının sürdürülebilir kalkınma için eğitim hakkındaki düşüncelerini belirlemek amacıyla yapılmışır. Bu çalışmanın amacına uygun olarak, amaçlı örnekleme tekniklerinden uygun örnekleme tercih edilmiştir. Yapılan çalışmanın örneklemini 30 sınıf öğretmeni adayı oluşturmaktadır. Araştırmada nitel araştırma yöntemlerinden olan olgu bilim (fenomenoloji) deseni kullanılmıştır. Araştırmada nitel yöntemlerde veri toplama tekniği olarak kullanılan görüşmeler ile veriler toplanmıştır. Çalışmada veri toplama aracı olarak araştırmacılar tarafından hazırlanan ve uzman görüşlerine göre son şekli verilen yarı yapılandırılmış görüşme formu kullanılmıştır. Elde edilen nitel veriler içerik analiz yöntemine göre betimlenmiştir. Sınıf öğretmeni adaylarının genel anlamda sürdürülebilir kalkınma için eğitim ile ilgili olumlu düşüncelere sahip olduğu tespit edilmiştir. Araştırmaya katılan sınıf öğretmeni adaylarının, sürdürülebilir kalkınma için eğitimin okul öncesi dönemden itibaren verilmesi gerektiğini belirtmişlerdir. Ayrıca, çalışmaya katılan öğretmen adayları tarafından sürdürülebilir kalkınma için eğitim de en etkili yöntemin okul dışı gezi programı olacağı ifade edilmiştir. Geri kalan katılımcıların bir kısmı drama bir kısmı da konuyla ilgili videolar izlettirmenin etkili yöntemler olabileceğini ifade etmişlerdir.

Anahtar kelimeler: sınıf öğretmeni adayları, sürdürülebilir kalkınma için eğitim, çevre eğitimi.

\footnotetext{
* This work presented as an oral presentation at $17^{\text {th }}$ International Primary Teacher Education Symposium in Gazi University, Ankara in April 2018.

${ }_{* * *}^{* *}$ Corresponding Author: Asst. Prof. Dr., Firat University, Elazı̆ğ, Turkey, mugras@ firat.edu.tr

Res. Asst., Firat University, Elazığ, Turkey, ezengin@ firat.edu.tr
} 


\section{Giriş}

Sanayi devrimi ile birlikte, dünyanın iklimi, ozon tabakası, okyanusların asitlik oranı, azot döngüsü, kimyasal kirlilik, kullanılabilir temiz su ve biyolojik çeşitliliklerde değişiklik meydana gelmiştir (Rockström ve diğerleri, 2009). İnsanlar, çevresel, sosyal ve ekonomik konular arasındaki ilişkilere dikkat etmediklerinden dolayı iklimi (Solomon ve diğerleri, 2007) ve ekosistemi (Millennium Ecosystem Assessment , 2005) olumsuz yönde etkilemektedirler. Mesela, bu yüzyılda hayvan türlerinin \%30'unun neslinin tükenme tehlikesi ile karşı karşıya olması (Día ve diğerleri, 2005), okyanus asitliğinin 2100 yılına kadar \%150 oranında artma riski (Caldeira \& Wickett, 2003) ve insan nüfusunun büyük bir kısmının 2025 yılına kadar temiz suya erişememe riski (UNPF, 2001) olumsuz etkilerin sonuçlarına örnek gösterilebilir. Her geçen gün dünyayı etkileyen çevresel, ekonomik ve sosyal sorunların sayısı artmaktadır. Bu sorunların çözümü için çalışmalar yapılmakta ama başarılı olunamamaktadır. Çözüm yollarının mevcut sorunları ortadan kaldırmaya ve farklı sorunların oluşmasını engellemeye yönelik olması gerekmektedir. Fakat sorunlar, sürdürülebilir bir bakış açısı ile ele alınmamaktadır. Buna bağlı olarak çevrede büyük değişimler meydana gelmektedir.

21. yüzyılda dünya çapında eğitim ile ilgili artan bir değişim hareketi vardır (Los, 2008; Pigozzi, 2003; Santone, 2003; Wakefield, 2003). Bu değişimlere, Birleşmiş Milletler Dünya Çevre ve Kalkınma Komisyonu Brundtland Raporunda (WCED, 1987) ilk kez tanıtılan sürdürülebilir kalkınmanın da dâhil edildiği görülmektedir.

1992 yılında, Birleşmiş Milletler Dünya Zirvesi'nin sürdürülebilir kalkınmayı dikkate alarak eğitimi yeniden şekillendirme çağrısı, sürdürülebilir kalkınma çalışmalarına önem verilmesini sağlamıştır (United Nations Division for Sustainable Development, 1993). Birleşmiş Milletler Eğitim, Bilim ve Kültür Örgütü (UNESCO), gelecek nesilleri dünya sorunlarına sürdürülebilir çözümler bulmaya hazırlamak için 2005 yılında başlayıp 2014 yılında tamamlanmış olan eğitim süresini 'Birleşmiş Milletler Sürdürülebilir Kalkınma için Eğitimin (SKE) 10 yılı’ olarak belirlemiştir.

Birleşmiş Milletler Çevre ve Kalkınma Komisyonu Brundtland Raporu, sürdürülebilir kalkınma için eğitimi, "şimdiki neslin, ihtiyaçlarını gelecek nesillerin de ihtiyaçlarını karşılayabilmeleri farkındalığıyla karşılaması" şeklinde tanımlamıştır (WCED, 1987: s.43). Mckeown (2014) ise sürdürülebilir kalkınma için eğitimi; öğrencilerin mevcut ve gelecek nesiller için sürdürülebilir bir dünyaya katkıda bulunmalarını sağlayan tutumların, değerlerin, becerilerin ve inançların geliştirilmesinde teşvik edici bir eğitim yaklaşımı şeklinde tanımlamıştır. Sürdürülebilir kalkınmanın çevresel, sosyal ve ekonomik olmak üzere üç boyutu bulunmaktadır (Soubbotina, 2004). Sürdürülebilir kalkınmanın boyutlarının ayrı ayrı değil bir bütün olarak düşünmek gerekmektedir (Altuntaş \& Türker, 2012; Öztürk-Demirbaş, 2011).

Sürdürülebilirlik bilgisi olmayan bireyler, iyi niyetli olsalar dahi sorunların çözümünde başarılı olamazlar hatta başka sorunlara da neden olabilirler. Etkili çözümler için geniş çaplı düşünmek ve bir kararın bütün olasılıklarını değerlendirerek çözümler geliştirmek gerekmektedir. Dünya genelinde mevcut sorunları çözmeye yönelik sorumluluk alan bireyler için bu özellikler önemlidir. Bireylerin bu sorunların çözümü için gösterdikleri çabaların başarısız sonuçlanması, bireylerin olumsuzluğa kapılarak 
sonraki süreçlerde sorunların çözümü için çaba göstermemelerine neden olabilmektedir (Doğru, 2008).

Pramling-Samuelsson (2011), erken çocukluk döneminin sürdürülebilir kalkınma için eğitimin tanıtımına yönelik kritik bir zaman olduğunu, bu dönemde küçük çocukların değer aktarımına duyarlı olduklarını ve bu konu ile ilgili mesajları içselleştirmeye hazır olduklarını vurgulamaktadır. $\mathrm{Bu}$ düşünceye paralel olarak sürdürülebilir kalkınma için eğitimin pek çok savunucusu, erken çocukluk döneminde, kavramların çocukların gelişimsel seviyelerine uygun olarak sunulmasıyla karmaşık kavramların bile içselleştirilebileceğini vurgulamaktadır (Bently \& Reppucci, 2013; Boutte, 2008; Davis, 2008; Davis, Engdahl, Otieno, Pramling-Samuelson, SirajBlatchford, \& Vallahh, 2009; Kahriman-Ozturk, Olgan, \& Güler, 2012; PramlingSamuelsson, 2011; Spearman \& Eckhoff, 2012; Wensing \& Torre, 2009). Bu bilgiler 1şığında okul öncesi ve sınıf eğitimine yönelik sürdürülebilir kalkınma için eğitim ile ilgili planlamalar yapılması önem taşımaktadır. Bu planlamaların uygulayıcıları olan öğretmenler sürdürülebilir kalkınma eğitiminin ana itici gücü ve etkili değişim aracıları olarak görülmektedirler (Habibah \& Punitha, 2012; Liu, 2009).

İnsanların içinde yaşadıkları Dünya'nın geleceği için büyük önem taşıyan sürdürülebilir kalkınma eğitimi ile ilgili yapılan çalışmalar incelendiğinde çalışmalarda genellikle nicel yöntemin kullanıldığı bununla birlikte öğretmen veya öğretmen adaylarının görüşlerinin alınmasına yönelik çalışmaların çok az olduğu belirlenmiştir. Öztürk-Demirbaş (2015) yaptığı çalışmada öğretmen adaylarının sürdürülebilir kalkınma farkındalık düzeylerini incelemiştir. Bu çalışma sonucunda, öğretmen adaylarının sürdürülebilir kalkınma farkındalık düzeylerinin "çevresel etik" ve "toplumsal-sosyal" faktörleri ve toplam puanları açısından "yüksek", "çevresel ekonomik" faktöründe ise "orta" düzeyde olduğu belirlenmiştir. Soysal (2016) sınıf öğretmen adaylarının sürdürülebilir kalkınma için eğitime yönelik yeterlik algılarını belirlemek amaçlı yaptığı çalışma sonucunda, öğretmen adaylarının yeterlik algılarının olumlu olduğu sonucuna ulaşmıştır. Gökmen, Solak ve Ekici (2017) çalışmalarında, öğretmen adaylarının sürdürülebilir kalkınma için eğitime yönelik tutumları ve bu tutumları ile ilişkili olan bazı faktörleri araştırmışlardır. Öğretmen adaylarının sürdürülebilir kalkınma için eğitime yönelik tutumlarının yüksek olduğu ancak başarı puanlarının düşük olduğu sonucuna ulaşılmıştır. Çobanoğlu ve Türer (2015) yaptıkları çalışmada fen bilgisi ve sosyal bilgiler öğretmen adaylarının sürdürülebilir kalkınma farkındalıklarının belirlenmesini amaçlamıştır. Araştırma sonucunda, öğretmen adaylarının sürdürülebilir kalkınma farkındalıklarının yüksek olduğunu belirlemişlerdir.

Herhangi bir eğitim reformu ve uygulaması, öğretmenlerin inançları, ön bilgileri, tutum ve görüşleri dikkate alındığında başarılı olabilir (Haney, Czerniak, \& Lumpe, 1996; Khader, 2012; Nespor, 1987; Zheng, 2009). Bu nedenle ülkemizde verimli bir sürdürülebilir kalkınma eğitimi konusunda başarılı uygulamalar yapılabilmesi için öğretmenlerin görüşlerinin alınması ve bu görüşler doğrultusunda düzenlemelerin yapılması gerekmektedir. Fakat literatürde öğretmen görüşlerini belirlemeye yönelik çok az sayıda çalışma bulunmaktadır. Bu nedenle yapılan bu çalışmanın literatüre katkı sağlayacağı düşünülmektedir.

$\mathrm{Bu}$ çalışmanın amacı; sınıf öğretmeni adaylarının sürdürülebilir kalkınma için eğitim hakkındaki görüşlerini belirlemektir. Bu amaca ulaşmak için aşağıdaki soruya cevap aranmıştır: 
Sınıf öğretmen adaylarının sürdürülebilir kalkınma için eğitime ilişkin görüşleri nasildir?

\section{Yöntem}

$\mathrm{Bu}$ araştırmada nitel araştırma yaklaşımlarından olgubilim deseni kullanılmıştır. Nitel yöntem, insanların hayatlarını nasıl algıladıkları ile ilgili bilgi geliştirmek, algılama sürecinin genel hatlarını çizmek ve insanların tecrübe ettikleri şeyleri nasıl yorumladıklarını tarif etmeye yarayan ayrıca olayı araştırmacının değil katılımcının penceresinden görebilmeyi sağlayan bir yöntemdir (Merriam, 2013). Olgubilim deseni ise günlük yaşantımızda karşılaştığımız fakat detaylı bilgi sahibi olmadığımız olguları detayı inceleyen nitel bir yaklaşım türüdür (Creswell, 2009). Tamamen yabancı olmadığımız fakat anlamını tamamen kavrayamadığımız olguları araştırmayı amaçlayan araştırmalar için olgubilim deseni uygun bir araştırma zeminidir (Yıldırım \& Şimşek, 2016). Olgubilim deseninde araştırmacı, çalışmaya katılan bireylerin olguları nasıl anladıklarını ve olgulara yükledikleri anlamı belirleyip tanımlama yapar. Bundan dolayı genellemeden ziyade olguları tanımlamak önemlidir (Akturan \& Esen, 2017). Bu çalışmada sınıf öğretmen adaylarının sürdürülebilir kalkınma için eğitim ile ilgili görüşlerini belirlemek amacıyla olgubilim deseni kullanılmıştır.

\section{Çalışma Grubu}

Nitel araştırma yöntemi kullanılarak yapılan çalışmalarda elde edilen sonuçlar, evrene genelleme kaygısı taşımaması ve çalışmaya konu olan olguların derinlemesine incelenmesi amaçlandığından dolayı bu tür çalışmalarda amaçlı örnekleme tekniği daha çok tercih edilmektedir (Creswell, 2009). Bu çalışmanın amacına uygun olarak amaçlı örnekleme tekniklerinden uygun örnekleme tercih edilmiştir. Amaca yönelik örneklemede, örneklemin büyüklüğü elde edilen bilgiler göz önünde bulundurularak belirlenir. Lincoln ve Guba eğer amaç bilgiyi artırmaksa seçim, örneklemden yeni bilgi elde edilemediğinde son bulacağını ifade etmiştir (Akt: Merriam, 2013). Bu bilgi 1şığında çalışma grubu ile yapılan görüşmelerde yeni bilgi gelmediğinden dolayı çalışma grubu 30 sınıf öğretmen adayı ile sınırlandırılmıştır. Araştırma Fırat Üniversitesi Eğitim Fakültesi Sınıf Öğretmenliği Bölümü 4. Sınıf öğrencileri ile gönüllülük esasına göre yapılmıştır. 4. Sınıf öğrencilerinin seçilmesinin nedeni ise lisans düzeyinde alacakları eğitimin son kademesinde olmaları ve mesleğe başlamaya yakın olmaları nedeniyle tercih edilmiştir. Araştırma etiği çerçevesinde araştırmaya katılan sınıf öğretmeni adayları, A1, A2, ...A30 şeklindeki kodlarla isimlendirilmiştir.

\section{Veri Toplama Aracı}

DeMarrais tarafından görüşme, yer aldığı, araştırma yapılan kapsama ilişkin hazırlanan sorulara odaklanarak araştırmacı ve katılımcının birlikte gerçekleştirdiği konuşma süreci olarak tanımlanmaktadır (Akt: Merriam, 2013). Görüşmenin temel amac1, katılımcının konuyla ilgili aklındaki şeyleri öğrenmektir (Patton, 2002). Bu çalışmada yarı yapılandırılmış görüşme türü kullanılmıştır. Yarı yapılandırılmış görüşme türünde katılımcının algıladığı dünyayı kendi ifadeleriyle anlatması sağlanır (Merriam, 2013). Görüşmede kullanılacak form, araştırmacılar tarafından ilk etapta altı sorudan oluşacak şekilde hazırlanmıştır. Daha sonra eğitim ve alan eğitimcisi iki uzmanın görüşleri alınmış ve bu görüşler doğrultusunda formdaki soru sayısı dörde 
düşürülerek son şekli verilmiştir. Öğretmen adaylarına yapılacak görüşmenin konusu hakkında bilgiler verilmiş daha sonra bir araştırmacı tarafından görüşmeler yapılmıştır.

\section{Geçerlik ve Güvenirlik}

$\mathrm{Bu}$ çalışmada geçerlik ve güvenirliği etkileyen faktörleri asgari düzeye indirmek için araştırmacılar tarafından çeşitli önlemler alınmıştır. Çalışmanın iç geçerliği için; araştırmacılar tarafından hazırlanan görüşme formunda uzman görüşlerine başvurulmuştur. Daha sonra iki farklı öğretmene görüşme formu okutularak formun anlaşılabilirliği açısından değerlendirmesi istenmiştir. Uzman ve öğretmen görüşlerine göre soruların uygunluğu ve anlaş1labilirliği ile ilgili alınan görüşler doğrultusunda görüşme formu düzenlenmiştir. Araştırmaya katılan öğretmen adaylarının sorulara verdikleri cevaplar tekrardan teyit ettirilmiştir. Görüşmeler yaklaşık 20-25 dakika sürmüştür. Öğretmen adaylarının verdikleri cevaplar bulgular kısmında alıntılar şeklinde sunulmuştur. Yapılan mülakatlar sonucunda elde edilen verilerin analizleri aşamasında, iki araştırmacının içerik analiz verileri ayrı ayrı kodlanmış ve aralarındaki tutarlılık, [Görüş birliği / (Görüş birliğgi + Görüş ayrılı̆̆ı) x 100] formülü kullanılarak hesaplanmıştır (Miles \& Huberman, 1994). Kodlamaları yapan araştırmacılar arasındaki uyum .85 olarak hesaplanmıştır. Veri çeşitlemesi yapılamaması, çalışmanın iç geçerliğini sınırlayacak faktörler arasında gösterilebilir. Çalışmanın dış geçerliği için araştırma yöntemi, çalışma grubu, veri toplama aracı, verilerin toplanması ve analizi ve daha sonra bulgular açıkça betimlenmiştir. Araştırmanın iç güvenirliğini sağlamak için yapılan görüşmeler ses kayıt cihazı kullanılarak yapılmış ve veri kaybı önlenmiştir. Ayrıca bulgular, araştırmacılar tarafından yorumlanmadan doğrudan sunulmuştur. Son olarak da elde edilen verilerin sonuç kısmında farklı çalışmalar ile tartışılması, çalışmanın dış güvenirliğini sağlamak açısından önemlidir. Araştırmacılar tarafından sonuçların tutarlı olduğu hususunda görüş birliğine varılmıştır.

\section{Veri Analizi}

Bazı bilim insanlarına göre tüm nitel veri analizleri içerik analizidir, çünkü tüm nitel veri analizlerinde üzerinde çalışılan, o verinin içeriğidir (Merriam, 2013). İçerik analizi, bir veya birden çok metnin içindeki sözcüklerin, kavramların, temaların, deyimlerin, karakterlerin veya cümlelerin varlıklarını belirlemek ve onları sayıya dökmek için kullanılır (Kızıltepe, 2017). İçerik analizinde ilk önce birbirine benzeyen nitel veriler belirli tema ve kategoriler şeklinde düzenlenir (Yıldırım \& Şimşek, 2016). $\mathrm{Bu}$ araştırmada sınıf öğretmeni adaylarının yöneltilen sorulara verdikleri cevaplar içerik analizi ile betimlenmiştir.

\section{Bulgular}

Araştırmaya katılan sınıf öğretmeni adayları ile sürdürülebilir kalkınma için eğitim ile ilgili yapılan görüşme verilerinin içerik analiz sonuçları aşağıda tablolar halinde sunulmuştur.

Sınıf öğretmeni adaylarının "Sürdürülebilir kalkınma için eğitim hakkında ne düşünüyorsunuz?" sorusuna verdikleri cevapların içerik analiz sonuçları Tablo 1' de sunulmuştur. 
Tablo 1

Sınıf Öğretmeni Adaylarının "Sürdürülebilir Kalkınma İçin Eğitim Hakkında Ne Düşünüyorsunuz?" Sorusuna Verdikleri Cevaplar

\begin{tabular}{lcc}
\hline Kodlar & $f$ & $\%$ \\
\hline Önemli & 18 & 60 \\
Yeterli bilgiye sahip değilim & 12 & 40 \\
\hline
\end{tabular}

Araştırmaya katılan sınıf öğretmeni adaylarının büyük bir kısmının sürdürülebilir kalkınma için eğitimin önemli olduğunu (\%60), geri kalan kısmının ise bu konu hakkında yeterli bilgiye sahip olmadıklarını belirttikleri tespit edilmiştir.

Araştırmaya katılan öğretmen adaylarının verdikleri örnek cevaplar aşağıda sunulmuştur:

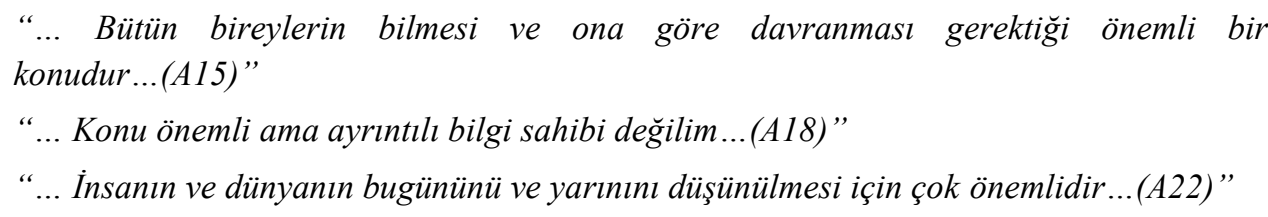

Sınıf öğretmeni adaylarının sürdürülebilir kalkınma için eğitim ile ilgili yeterli bilgiye sahip olmamaları, lisans eğitiminde bu konuyla ilgili herhangi bir ders almamalarının bir sonucu olduğu düşünülmektedir.

Sınıf öğretmeni adaylarının "Sürdürülebilir kalkınma için eğitime hangi dönemden itibaren başlanmalıdır?" sorusuna verdikleri cevapların içerik analiz sonuçları Tablo 2' de sunulmuştur.

\section{Tablo 2}

Sınıf Öğretmeni Adaylarının "Sürdürülebilir Kalkınma İçin Eğitime Hangi Dönemden İtibaren Başlanmalıdır?" Sorusuna Verdikleri Cevaplar

\begin{tabular}{lll}
\hline Kodlar & $f$ & $\%$ \\
\hline Okul öncesi dönemden itibaren başlanmalı & 15 & 50 \\
Ailede başlanması & 10 & 33.34 \\
İlkokul döneminde başlanması & 5 & 16.66 \\
\hline
\end{tabular}

Sınıf öğretmeni adaylarının büyük bir kısmı, sürdürülebilir kalkınma için eğitimin okul öncesi dönemden itibaren başlaması gerektiğini (\%50), belirli bir kısım öğretmen adayı ise ailede başlaması gerektiğini belirtmişlerdir. (\%33.34). Geri kalan öğretmen adayları ise ilkokul döneminden itibaren başlaması gerektiğini belirtmişlerdir (\%16.66). Sürdürülebilir kalkınma için eğitime yönelik yeterli bilgisi olmadığını belirten öğretmen adaylarının bu soruyu cevapladığı görülmüştür.

Araştırmaya katılan öğretmen adaylarının verdikleri örnek cevaplar aşağıda sunulmuştur:

\footnotetext{
“... Kesinlikle erken yaşlardan itibaren başlanmalıdır...(A12)”

“... Eğitim öğretimin ilk kademesi olan okul öncesi dönem bence uygundur ...(A8)”

“... Bence en uygun dönem, çocukların tam anlamıyla akademik bilgilerle tanışmaya başladıkları dönem olduğu için ilkokul kademesidir...(A5)”,
} 
Bireylerdeki birçok temel beceri ve tutumlar okul öncesi döneminden itibaren şekillenmeye başlamaktadır. $\mathrm{Bu}$ nedenle araştırmaya katılan öğretmen adaylarının sürdürülebilir kalkınma için eğitime okul öncesi dönemden itibaren başlanması ile öğrencilerde olması istenilen becerilerin ve tutumların kazandırılacağı düşünülmektedir.

Sınıf öğretmeni adaylarının "Sürdürülebilir kalkınma için eğitim ile ilgili ne tür yöntemler kullanılabilir?" sorusuna verdikleri cevapların içerik analiz sonuçları Tablo 3' de sunulmuştur.

Tablo 3

Sınıf Öğretmeni Adaylarının "Sürdürülebilir Kalkınma İçin Eğitim ile İlgili Ne Tür Yöntemler Kullanilabilir?" Sorusuna Verdikleri Cevaplar

\begin{tabular}{lll}
\hline Kodlar & $f$ & $\%$ \\
\hline Okul dışı gezi programları & 18 & 60.00 \\
Drama & 8 & 26.67 \\
Video & 4 & 13.33 \\
\hline
\end{tabular}

Öğretmen adaylarının büyük bir kısmı sürdürülebilir kalkınma için eğitimin en uygun okul dışı gezi programları gerçekleştirerek etkili olabileceğini ifade etmişlerdir. Geri kalan katılımcıların bir kısmı drama bir kısmı da oyunlar diyerek en etkili eğitimin olabileceğini düşündükleri yöntemleri belirtmişlerdir. Sürdürülebilir kalkınma için eğitime yönelik yeterli bilgisi olmadığını belirten öğretmen adaylarının bu soruyu cevapladığı görülmüştür.

Araştırmaya katılan öğretmen adaylarının verdikleri örnek cevaplar aşağıda sunulmuştur:

“... Konu dünya ile ilgili olduğu için okul dlşı gezilerinin en etkili yöntem olduğunu düşünüyorum...(A16)”

“... Okul öncesi dönem öğrencileri için en uygun yöntem oyundur...(A30)”

Araştırmaya katılan öğretmen adaylarının belirttikleri yöntemler öğrencilerin konu ile ilgili olarak gerçek hayatla ilişki kurup tecrübe yaşamalarını sağlayacaktır. Buna bağlı olarak da öğrencilerde beklenilen beceri ve tutumlarının gelişeceği düşünülmektedir. 
Sınıf öğretmeni adaylarının "Sürdürülebilir kalkınma için eğitim süreci nasıl olmalıdır?" sorusuna verdikleri cevapların içerik analiz sonuçları Tablo4' de sunulmuştur.

Tablo 4

Sınıf Öğretmen Adaylarının "Sürdürülebilir Kalkınma İçin Eğitim Süreci Nasıl Olmalıdır?" Sorusuna Verdikleri Cevaplar

\begin{tabular}{lll}
\hline Kodlar & $f$ & $\%$ \\
\hline Sınıf dışında yapılmalı & 13 & 43.34 \\
Videolar ve materyaller kullanılmalı & 6 & 20.00 \\
Drama kullanılmalı & 5 & 16.67 \\
Değerler eğitiminden yararlanılmalı & 4 & 13.34 \\
Ailelerin eğitim sürecine katılması sağlanmalı & 2 & 6.67 \\
\hline
\end{tabular}

Araştırmaya katılan sınıf öğretmeni adaylarının sürdürülebilir kalkınma için eğitim sürecinin sınıf dışında, uygun materyaller kullanarak, drama yaparak, değerler eğitimi şeklinde ve ailelerin bilinçlendirilmesi ile eğitim öğretim sürecinin şekillendirilmesi gerektiğini belirtmişlerdir. Sürdürülebilir kalkınma için eğitime yönelik yeterli bilgisi olmadığını belirten öğretmen adaylarının bu soruyu cevapladığı görülmüştür.

Araştırmaya katılan öğretmen adaylarının verdikleri örnek cevaplar aşağıda sunulmuştur:
“...Konu dünya ile ilgili olduğu için sürecin ağırllklı olarak slnıf dışında yapılmasının uygun olacağını düşünüyorum...(A16)"
“... Konu kapsamında bilgilerin belirli değerler ile bağlantısı olduğu için, direkt akademik bilgi olarak değil de değerler şeklinde verilmesi gerektiğini düşünüyorum...(A11)”
“... Eğitim öğretim sürecinde, konu ile ilgili bol miktarda materyal kullanılması ile farkındalık oluşacağını düşünüyorum...(A28)"

Araştırmaya katılan öğretmen adayları tarafından önerilen sürdürülebilir kalkınma için eğitim sürecinin, öğrencilerde konu ile ilgili içerik, konu ilgisi ve katılımını arttırmaya yardımcı olacak ve öğrenciler ile duygusal olarak bağlantı kurulmasını sağlayacak şekilde olduğu düşünülmektedir.

\section{Sonuç ve Tartışma}

$\mathrm{Bu}$ çalışmada, sınıf öğretmeni adaylarının sürdürülebilir kalkınma için eğitim konusu hakkındaki düşünceleri belirlenmiştir.

Araştırmaya katılan sınıf öğretmeni adaylarının büyük bir kısmının sürdürülebilir kalkınma için eğitimin önemli olduğunu, geri kalan kısmının ise bu konu hakkında yeterli bilgiye sahip olmadığını belirttiği belirlenmiştir. Literatürde yapılan çalışmalarda, öğretmenlerin sürdürülebilir kalkınma için eğitimin felsefesi, pedagojisi, potansiyel kaynakları ve sınıf materyalleri hakkındaki bilgilerinin sınırlı olduğu, ancak bunu uygulama konusundaki tutumlarının genellikle olumlu olduğuna yönelik sonuçlara ulaşı1mıştır (Burmeister \& Eilks, 2013; Burmeister, Schmidt-Jacob, \& Eilks, 2013). Şahin, Ertepınar ve Teksöz (2009) yaptıkları çalışmada, üniversite öğrencilerinin 
çoğunun sürdürülebilir kalkınma terimine aşina oldukları fakat sürdürülebilir kalkınmaya ilişkin kapsayıcı bir bakış açısına sahip olmadıkları sonucuna ulaşmışlardır. Almanya, Avustralya ve İsrail gibi birçok ülkedeki öğretmen eğitim programları kapsamında sürdürülebilirlik eğitimi ile ilgili dersler bulunmaktadır (Abramovich \& Loria, 2015; Andersson, 2017). Avustralya'daki James Cook Üniversitesi, birinci sinıf öğretmen adayları için Sürdürülebilirlik Eğitimi verilmeye başlanmasıyla birlikte, öğretmen adaylarının sürdürülebilir kalkınma için eğitim kapsamında olan konulara yönelik bilgi ve ilgilerinin arttı̆̆ inançlarının geliştiği belirlenmiştir (Tomas, Girgenti, \& Jackson, 2017). Literatürdeki diğer çalışmalarda öğretmen adaylarının sürdürülebilirlik eğitimi ile ilgili aldıkları derslerin onların konu ile ilgili bilgi ve inançlarını arttırdığı tespit edilmiştir (Abramovich \& Loria, 2015; Andersson, 2017; Buchanan \& Crawford, 2015). Öğretmen eğitiminde beklenilen hedeflere ulaşılması için sürdürülebilir kalkınma için eğitim kapsamında, öğretmen adayları tarafından gerekli eğitimler alınmalı ve bunların öğrencilere öğretimi ile ilgili tecrübeler yaşamaları gerekmektedir (Santone, Saunders, \& Seguin, 2014). Ülkemizde 2018-2019 eğitim öğretim yılına kadar öğretmen eğitimi kapsamında sürdürülebilir kalkınma için eğitime yönelik herhangi bir ders bulunmamaktaydı. 2018-2019 eğitim öğretim yılından itibaren uygulanmaya başlayan sınıf eğitimi lisans programında "Sürdürülebilir Kalkınma ve Eğitim" isimli bir ders meslek bilgisi seçmeli dersler arasına eklenmiştir. Ancak bunun hem meslek dersleri arasında olması hem de seçmeli bir ders olarak eklenmesi, istenilen başarılı sonuçların alınması noktasında eksiklik oluşturabileceği düşünülmektedir. Öğretmen adaylarında küresel meselelere karşı farkındalık yaratmak ve konu ile ilgili disiplinler arası bir alt yapı oluşmasını sağlamak için zorunlu dersler arasında verilmesi gerektiği düşünülmektedir. Bu çalışma sonucunda öğretmen adaylarının sürdürülebilir kalkınma için eğitim ile ilgili yeterli bilgiye sahip olmamaları, lisans eğitiminde bu konuyla ilgili herhangi bir ders almamalarının bir sonucu olarak düşünülmektedir.

Sınıf öğretmen adaylarının büyük bir kısmının sürdürülebilir kalkınma için eğitimin okul öncesi dönemden itibaren başlaması gerektiğini, belirli bir kısım öğretmen adayı ise ailede başlaması gerektiğini belirtmiştir. Literatürde okul öncesi dönemde sürdürülebilir kalkınma için eğitiminin önemine vurgu yapan çalışmalar bulunmaktadır. Aini ve Laily (2010) tarafından, okul öncesi öğretmenlerinin çocuklara sürdürülebilirlik kavramını anlamalarını sağlamak için ilk adımı atmaları gerektiği vurgulanmaktadır. Kahriman-Ozturk ve Olgan (2016) tarafindan yapılan çalışmada, okul öncesi dönemde sürdürülebilir kalkınma için eğitim ile ilgili farkındalık oluşturmanın önemi vurgulanmaktadır. Green (2013) tarafindan yapılan çalışmada, okul öncesinde sürdürülebilir kalkınma için eğitimin önemli olduğu ve bu dönemdeki eğitimin, çocukların gelişimine olumlu katkı sağladığı tespit edilmiştir. Çocukların yaşantılarındaki elektronik eşyaların sayısının fazla olması, birçok çocuğun doğadan uzak şehir merkezlerinde yetişiyor olması, doğal ve sağlıklı gıda ürünlerine ulaşma şartlarının zorlaşması ve bunlara benzer nedenlerden dolayı sürdürülemeyen kalkınmanın en çok çocukların yaşamını etkilemesi, okul öncesi dönemde verilecek olan sürdürülebilirlik için eğitimin nedenlerinden birini oluşturmaktadır (GülayOgelman, 2012). Günümüzün çocukları, geleceğin yetişkinleri olarak toplumun içinde sürdürülebilir bir hayat için önemli bir rol oynamaktadır (Siraj-Blatchford \& PramlingSamuelsson, 2016). Okul öncesi dönem eğitiminin diğer eğitim kademelerine göre 
sürdürülebilirlik kavramının öğretimi ile daha yakından ilgilidir (Haddan, 2008). Bireylerin birçok konuda olduğu gibi sürdürülebilirliğe yönelik görüşleri ve tutumları da, okul öncesi döneminden itibaren şekillenmeye başlamaktadır. Bu dönemde verilecek doğru bir eğitimin, ilerleyen yıllarda sürdürülebilir bir yaşam biçimine sahip olma konusunda etkili olacağı düşünülmektedir. $\mathrm{Bu}$ nedenle çocukların sürdürülebilir bir yaşamda etkili bir rol almaları için okul öncesi dönemden itibaren edindikleri tecrübeler önem kazanmaktadır (Didonet, 2008). Eğitim yoluyla, özellikle sürdürülebilir kalkınma için eğitime ilişkin konuların tam olarak anlaşılmasıyla birlikte değerler ve tutumlardaki değişiklikler, beceriler ve davranışlar elde edilebilir (Scott, 2013). Bu bilgiler 1şığında okul öncesi öğretmenlerin öğrencilere sürdürülebilirlik kavramını kavratıp, onlarda olumlu tutum ve istenilen becerilerin kazandırılmasına yönelik eğitim öğretim süreci planlayıp uygulaması büyük önem taşımaktadır.

Öğretmen adaylarının büyük bir kısmı sürdürülebilir kalkınma için eğitime yönelik en uygun yöntemin okul dışı gezi programları olduğunu belirtmişlerdir. Geri kalan katılımcıların bir kısmı drama bir kısmı da konuyla ilgili videolar izlettirmenin etkili yöntemler olabileceğini ifade etmişlerdir. Hanıfah, Shaharuddin, Noraziah ve Mohamad Suhaily Yusry (2015) tarafından sürdürülebilir kalkınma eğitiminin, çeşitli yaklaşımlarla, sadece okul ortamında değil okul dışında da öğrencilerin ve öğretmenlerin genel farkındalığını arttırabileceği vurgulanmaktadır. Eileen, Leanna ve Annie (2018) tarafından yapılan çalışmada, öğretmen adaylarının sürdürülebilir kalkınma eğitimi için en uygun yöntemin video izletmek olduğuna yönelik görüşleri belirlenmiştir. Ayrıca Shelton, Archambault ve Hale (2017) ve Shelton, Hale ve Archambault (2016) yaptıkları çalışmalarda derslerde video kullanmanın yararlı olduğuna yönelik sonuçlara ulaşıldığı tespit edilmiştir. Bunların dışında literatürde sürdürülebilir kalkınma için eğitime ilişkin kullanılan ve başarılı sonuçlar alınan yöntemler de bulunmaktadır. Örneğin medya, lisans öğrencilerinin çevresel tutumlarını, endişelerini ve davranışlarını güçlü bir şekilde etkilediği ve medya okuryazarlığının sürdürülebilirlik eğitimi girişimlerinin önemli bir bileşeni olduğu tespit edilmiştir (Keinonen, Palmberg, Kukkonen, Yli-Panula, Persson \& Vilkonis, 2016). Benzer şekilde, sürdürülebilirlik konularına ilişkin güncel kitapların, sürdürülebilirlik eğitimi için önemli bir araç olduğu ve sürdürülebilirlik kavramlarını ve temalarını derslere entegre edilmesinin önemli olduğu belirlenmiştir (Bradbery, 2013). Eileen, Leanna ve Annie (2018) tarafından yapılan çalışmada sürdürülebilir kalkınma için eğitim konusunda, dijital hikayeler aracılığıyla öğrencilere karmaşık sürdürülebilirlik konuları, uluslararası çekimler ile ilişkilendirilebilir videolar kullanılarak, makaleler veya ders kitaplarından daha etkili olarak sunulabileceği tespit edilmiştir. Dijital hikayeler, görsellerin, grafiklerin, hareketli görüntülerin ve sesin bütünleştirilmesi yoluyla bilgi aktarımı yaparak öğrenmeyi destekleyebilmektedir (Hibbing \& Rakin-Erikson, 2003).

Araştırmaya katılan sınıf öğretmen adaylarının sürdürülebilir kalkınma için eğitim sürecinin sınıf dışında, videolar ve uygun materyaller kullanarak, dramalar yaparak, değerler eğitimi şeklinde ve ailelerin bilinçlendirilmesi şeklinde olması gerektiğini belirtmişlerdir. Hart (2003), çevre eğitimi programlarının hedefine ulaşabilmesi için kişisel olarak değer geliştirilmesi, sınıflarda ve okullarda uygulamalı faaliyetlerde bulunulması gerektiğini belirtmiştir. Ayrıca Alagöz (2007) sürdürülebilir kalkınmanın gerçekleşebilmesi için bireylerin etkin katılımının sağlanması gerektiğini ifade etmiştir. Burmeister, Schmidt-Jacob ve Eilks (2013), öğretim materyallerinin 
erişilebilir olmasıyla sürdürülebilir kalkınma için eğitimde başarılı olunabileceğini belirtmiştir. Sürdürülebilir kalkınma eğitimi, dünyadaki değişimlere paralel olarak değer, düşünme, metodoloji ve yapılandırılmış politika yapma kararını vurgulayan disiplinli bir öğrenme stratejisi olduğu için, toplumun her seviyesinden tam bir bağlılık olması gerektiği sonucuna varılabilir (Lampa, Greculescu, \& Todorescu, 2013). Bu bağlılığın oluşması için ailelerin sürdürülebilir kalkınma konusunda bilinçlendirilmesinin önemli olduğu düşünülmektedir. Öğretmen adaylarının sürdürülebilir kalkınma için eğitime yönelik olarak belirttikleri okul dışı gezi programları, drama ve konu ile ilgili videoların izlettirilmesi öğrencilerin gerçek hayatla ilişki kurup tecrübe yaşamalarını sağlamaktadır. Örneğin, öğrenciler Afrika kıtasındaki bazı ülkelerdeki insanların ihtiyacı olan temiz içme suyuna erişememenin, onları nasıl olumsuz etkilediğini videolarla somutlaştırılması etkili olacaktır. Ayrıca yapılabilecek okul dışı gezi programları öğrencilerin yaşanılan olumsuzlukları direkt görmelerini sağlayacaktır. Sonuç olarak bu yöntemler kullanılarak sürdürülebilir kalkınma için eğitim kapsamına girecek içerik, konu ilgisi ve katılımını arttırmaya yardımcı olacak ve öğrenciler ile duygusal olarak bağlantı kurulması sağlanacaktır (LaMarre \& Landreville, 2009).

\section{Öneriler}

Çalışmada elde edilen sonuçlara göre aşağıdaki hususlar önerilmektedir:

- Eğitim öğretimin her kademesindeki programların, sürdürülebilir kalkınma için eğitimin gereksinimlerini karşılayacak şekilde düzenlenmesi gerekmektedir.

- Öğretmenlerin sürdürülebilirlik kavramı ve kapsamı hakkında hizmet içi eğitim almaları gerekmektedir. Bu eğitim kapsamında literatürde yapılan çalışmalar sonucunda etkili olduğu belirlenen yöntemlerin öğretimine yönelik konuların olmas1 gerekmektedir.

- Öğretmenlerin sürdürülebilir kalkınma için eğitime ilişkin projeler hazırlamaları teşvik edilmelidir.

- Öğretmen yetiştirme lisans programlarında seçmeli olarak bulunan "Sürdürülebilir Kalkınma ve Eğitim" dersinin zorunlu dersler kapsamına alınması gerekmektedir.

- Velilerin sürdürülebilirlik kavramı ve kapsamı hakkında bilgilendirilmesi geremektedir. 


\section{Summary}

Purpose and Significance: Along with the industrial revolution, the climate of the earth, the ozone layer, the acidity ratio of the ocean, the nitrogen cycle, chemical pollution, available clean water and biological diversity have changed. Because people do not pay attention to the relationship between environmental, social and economic issues, they affect the climate and the ecosystem in a negative way. The number of environmental, economic and social problems that are affecting the world is increasing day by day. Some work is being done to solve these problems, but it is not successful. The solution must be to remove the existing problems and to prevent the occurrence of different problems. But the problems are not addressed from a sustainable point of view. As a result, major changes occur in the environment. In the 21 st century, there is an increasing shift in education around the world, which includes the first sustainable development introduced in the United Nations World Commission on Environment and Development's Brundtland Report. In 1992, the United Nations World Summit call for reshaping education, taking into account sustainable development, ensured that sustainable development work was emphasized. Even if they are benevolent, individuals without sustainability knowledge cannot succeed in solving problems or even cause other problems. It is necessary to think broadly about effective solutions and to develop solutions by evaluating all the possibilities of a decision. These characteristics are important for individuals who are responsible for solving existing problems worldwide. Any educational reform and implementation can be successful if teachers' beliefs, prior knowledge, attitudes and views are taken into consideration. For this reason, in order to implement successful implementations in an effective sustainable development education in our country, it is necessary to take the opinions of the teachers and make arrangements in line with these opinions. However, there are very few studies to determine their opinions in the literature. It is thought that this study made for this reason will contribute to the literature. The purpose of this study is; class teacher candidates should consider their views on education for sustainable development.

Method: In this research, phenomenology has been used as a qualitative research approach. In the phenomenological approach, the researcher identifies and defines the meanings of the individuals involved in the study and how they perceive the events. In this study, phenomenological approach was used to determine the opinions of prospective primary school teachers about education for sustainable development. For the purpose of this study, appropriate sampling was preferred from the purposeful sampling techniques. In the intended sample, the size of the sample is determined by considering the information. If the goal is to increase knowledge, the choice ends when no new information is available from the sampling units. Since there is no new information on the interviews with the working group in this information, 30 class teacher candidates are working group. The semi-structured interview form developed by the researchers was used as data collection tool and the obtained data was described using the content analysis technique.

Results: It has been determined that most of the class teacher candidates participating in the research are important for education for sustainable development, while the rest of them indicate that they do not have enough knowledge about this topic. Studies in the 
literature have found that teachers' knowledge of pedagogy, pedagogy, potential resources, and class materials for sustainable development is limited, but their attitudes to practice are generally positive. The results obtained in the study are in parallel with the literature. The majority of classroom teacher candidates stated that education for sustainable development should start from the pre-school period, while a certain part of the teacher candidates say they should start in the family. The remaining teacher candidates stated that they should start from primary school period. In the literature, results have been reached indicating that it is important to create awareness about education for sustainable development in preschool period, along with studies indicating that pre-school teachers should take the first step to ensure children understand the concept of sustainability. In addition, there are studies that indicate that education for sustainable development is important before school, and that education at this time is positively contributing to the development of children. The results obtained in the study are in parallel with the literature. A large proportion of the teacher candidates indicated that the most appropriate way to train for sustainable development was out-of-school excursion programs. Some of the remaining participants expressed that drama might be effective methods of watching related videos. There are studies in the literature that indicate that sustainable development education can increase the general awareness of students and teachers not only in the school environment but also outside the school, through various approaches. In addition, there are also study results that the most suitable method for teacher candidates for sustainable development education is to watch video. The class participating in the research stated that the educational process for sustainable development should be in the form of videos and appropriate materials, dramas, values education, and raising awareness of families outside the classroom. The answers of the teacher candidates are in accordance with the results of the studies in the literature. 


\section{Kaynakça}

Abramovich, A., \& Loria, Y. (2015). The long-term impact of an education for sustainability course on Israeli science and technology teachersí pro-environment awareness, commitment and behaviour. Australian Journal of Environmental Education, 31(2), 264-279.

Akturan, U., \& Esen, A. (2017). Sosyal bilimlerde bilgisayar destekli nitel araştırma yöntemleri. Ankara: Seçkin.

Altuntaş, C., \& Türker, D. (2012). Sürdürülebilir tedarik zincirleri: sürdürülebilirlik raporlarının içerik analizi. Dokuz Eylül Üniversitesi Sosyal Bilimler Enstitüsü Dergisi, 14(3), 39-64.

Andersson, K. (2017). Starting the pluralistic tradition of teaching? Effects of education for sustainable development (ESD) on pre-service teachersí views on teaching about sustainable development. Environmental Education Research, 23(3), 436449 .

Bently, D., \& Reppucci, A. (2013). I think they all felt distressed: Talking about complex issues in early childhood. Childhood Education, 89(1), 9-14.

Boutte, G. (2008). Beyond the illusion of diversity: How can early childhood teachers can promote social justice. The Social Studies, 99(4), 165-173.

Bradbery, D. (2013). Bridges to global citizenship: Ecologically sustainable futures utilising childrenís literature in teacher education. Australian Journal of Environmental Education, 29(02), 221-237.

Buchanan, L. B., \& Crawford, E. O. (2015). Teaching for sustainability in a social studies methods course: Opportunities and challenges. Social Studies Research and Practice, 10(2), 135-158.

Burmeister, M., Schmidt-Jacob, S., \& Eilks, I. (2013). German chemistry teachers' understanding of sustainability and education for sustainable development-an interview case study. Chemistry Education Research and Practice, 14, 169-176.

Caldeira, K., \& Wickett, M. E. (2003). Anthropogenic carbon and ocean pH. Nature, $425,365-371$.

Creswell, J. W. (2009). Research design, qualitative, quantitative, and mixed methods approaches (Third Edition). California: SAGE Publications.

Çobanoğlu, O., \& Türer, B. (2015). Fen bilgisi ve sosyal bilgiler öğretmenlerinin sürdürülebilir kalkınma farkındalıklarının belirlenmesi. Uluslararası Türk Ĕ̆itim Bilimleri Dergisi, 2(5), 235-247.

Davis, J. (2008). What might education for sustainability look like in early childhood? In Pramling-Samuellson, I. \& Kaga, Y. (Eds.), The contribution of early childhood education to a sustainable society (18-24). Paris: UNESCO.

Davis, J., Engdahl, I., Otieno, L., Pramling-Samuelson, I., Siraj-Blatchford, J., \& Vallahh, P. (2009). Early childhood education for sustainability: Recommendations for development. International Journal of Early Childhood, 41(2), 113-117.

Díaz, S., Tilman, D., Fargione, J., Stuart Chapin III, F., Dirzo, R., Kitzberger, T., \& Eardley, C. (2005). Biodiversity regulation of ecosystem services. In H. Hassan, R. Scholes, \& N. Ash (Eds.), Ecosystems and human well-being: Current stateand trends (pp. 297-329). Washington, DC: Island. 
Didonet, V. (2008). Early childhood education for a sustainable society. The Contribution of Early Childhood Education to A Sustainable Society, 14, 25-31.

Doğru, M. (2008). The application of problem solving method on science teacher trainees on the solution of the environmental problems. International Journal of Environmental and Science Education, 3(1), 9-18.

Eileen, G. M., Leanna, A., \& Annie E.H. (2018). Sustainability education in elementary classrooms: reported practices of alumni from a pre-service teacher course. Discourse and Communication for Sustainable Education, 9(1), 18-35.

Gökmen, A., Solak, K., \& Ekici., G. (2017). Sürdürülebilir kalkınma için eğitim: öğretmen adaylarının tutumları ile ilişkili olan faktörler. Kesit Akademi Dergisi, 3(12), 462-480.

Gülay-Ogelman, H. (2012). Teaching preschool children about nature: A project to provide soil education for children in Turkey. Early Childhood Education Journal, 40(3), 177-185.

Habibah L., \& Punitha, M. (2012). Amalan pengajaran pendidikan alam sekitar di Institut Pendidikan Guru, Kampus Pulau Pinang. Geografia-Malaysian Journal of Society and Space, 8(2), 1-6.

Haddad, L. H. (2008). For a specific dignity of ECE: Policy and research issues relating the education of young children and sustainable society. In I. Pramling Samuelsson \& Y. Kaga (Eds.), The contribution of early childhood education for a sustainable society (pp. 31-36). Paris: UNESCO.

Haney, J., Czerniak, C., \& Lumpe, A. (1996). Teacher beliefs and intentions regarding the implementation of science education reform strands. Journal of Research in Science Teaching, 33(9), 971-993.

Hanifah, M., Shaharuddin, A., Noraziah, A., \& Mohamad Suhaily Yusry, C. N. (2015). Sustainable level of use among teachers in Puchong, Selangor. Human Sciences, 5(1), 19-26.

Hibbing, A. N., \& Rakin-Erikson, J. L. (2003). A picture is worth a thousand words: using visual images to improve comprehension in middle school struggling readers. The Reading Teacher, 56(8), 758-770.

Kahriman-Ozturk, D. , Olgan, R., \& Guler, T. (2012). Preschool children's ideas on sustainable development: how preschool children perceive three pillars of sustainability with the regard to 7R. Educational Sciences: Theory and Practice. 12(4), 2987-2995.

Keinonen, T., Palmberg, I., Kukkonen, J., Yli-Panula, E., Persson, C., \& Vilkonis, R. (2016). Higher education studentsí perceptions of environmental issues and media coverage. Discourse and Communication for Sustainable Education, 7(1), 5-22.

Khader, F.R. (2012). Teachers' pedagogical beliefs and actual classroom practices in social studies instruction. American International Journal of Contemporary Research, 2(1), 73-92.

Kızıltepe, Z. (2017). İçerik analizi. F. N. Seggie ve Y. Bayyurt (Eds.), Nitel araştırma: yöntem, teknik, analiz ve yaklaşımları.(s. 253-266) içinde. Ankara: Anı Yayıncılık.

LaMarre, H. L., \& Landreville, K. D. (2009). When is fiction as good as fact? Comparing the influence of documentary and historical reenactment films on

(C) 2019 AKU, Kuramsal Eğitimbilim Dergisi - Journal of Theoretical Educational Science, 12(1), 298-315 
engagement, affect, issue interest, and learning. Mass Communication and Society, $12,537-555$.

Lampa, I., Greculescu, A., \& Todorescu, L.-L. (2013). Education for sustainable development - Training the young generation for the Future. Procedia - Social and Behavioral Sciences, 78, (120-124).

Liu, J. (2009). Education for sustainable development in teacher education: Issues in the case of York University in Canada. Asian Sosial Science, 5(5), 46-49.

Los, F. (2008). Worldly education. Alternatives Journal, 34(5), 26-27.

McKeown, R. (2014). The leading edge of teacher education and ESD. Journal of Education for Sustainable Development, 8(2), 127-131.

Merriam, S. B. (2013). Nitel araştırma desen ve uygulama için bir rehber (Çev. : Selahattin Turan, Çev. Ed.: Selahattin Turan). Ankara: Nobel yayın dağıtım.

Miles, M, B., \& Huberman, A. M. (1994). Qualitative data analysis: An expanded Sourcebook (2nd ed.). Thousand Oaks, CA: Sage.

Millennium Ecosystem Assessment. (2005). Ecosystems and human well-being: Synthesis. Washington, DC: Island.

Nespor, J. (1987). The role of beliefs in the practice of teaching. Journal of Curriculum Studies, 19(4), 317-328.

Öztürk-Demirbaş, Ç. (2015). Öğretmen adaylarının sürdürülebilir kalkınma farkındalık düzeyleri. Marmara Coğrafya Dergisi, 31, 300-316.

Patton, M. Q. (2002). Qualitative research and evaluation methods (Third Edition). California: Sage Publications.

Pigozzi, M. (2003). UNESCO and the international decade of education for sustainable development. UNESCO International Science, Technology \& Environmental Education Newsletter, 28(1), 1-7.

Pramling Samuelsson, I. (2011). Why we should begin early with ESD: The role of early childhood education. International Journal of Early Childhood. 43(2), 103118.

Rockström, J., Steffen, W., Noone, K., Persson, A., Stuart Chapin III, F. F., Lambin, E., \& Falkenmark, M. (2009). Planetary boundaries: Exploring the safe operating space for humanity. Ecology \& Society, 14(2), 1-33.

Santone, S. (2003). Education for sustainability. Educational Leadership, 61(4), 60-63.

Santone, S., Saunders, S., \& Seguin, C. (2014). Essential elements of sustainability in teacher education. Journal of Sustainability Education, 6. Retrieved from http://www.jsedimensions.org/wordpress/wp-content/uploads/2014/05/Santone-EtAl-JSE-May-2014-PDF-Ready.pdf

Seggie, F. N., \& Bayyurt, Y. (Eds.). (2017). Nitel araştırma: yöntem, teknik, analiz ve yaklaşımları. Ankara: Anı Publication.

Shelton, C., Warren, A., \& Archambault, L. (2016). Exploring the use of interactive digital storytelling video: promoting student engagement in a university hybrid course. TechTrends, 60(5), 465-474. 
Shelton, C., Archambault, L., \& Hale, A. (2017). Bringing digital storytelling to the elementary classroom: Video production for pre-service teachers. Journal of Digital Learning in Teacher Education, 33(2), 58-68.

Siraj-Blatchford, J., \& Pramling Samuelsson,I. (2016). Education for sustainable development in early childhood care and education, In Siraj-Blatchford, J., Mogharreban, C., \& Park, E. (Eds), International research on education for sustainable development in early childhood, International Perspectives on Early Childhood Education and Develpment, ss:1-15.Switzerland: Springer Books.

Solomon, S., Qin, D., Manning, M., Chen, Z., Marquis, M., Averyt, K. B., ... Miller, H. L. (Eds.). (2007). Climate change 2007 - the physical science basis: Contribution of working group I to the fourth assessment report of the IPCC. New York, NY: Cambridge University.

Soubbotina, T. P. (2004). Beyond economic growth an introduction to sustainable development (2nd Edition). USA: World Bank.

Soysal, N. (2016). Pre-Service classroom teachers' perceived competencies on education for sustainable development (Doctorate Thesis). Middle East Technical University, Ankara.

Spearman. M, \& Eckoff.A (2012). Teaching young learners about sustainability. Childhood Education, 8(6), 354-359.

Tomas, L., Girgenti, S., \& Jackson, C. (2017). Pre-service teachersí attitudes toward education for sustainability and its relevance to their learning: implications for pedagogical practice. Environmental Education Research, 23(3), 1-24. DOI: 10.1080/13504622.2015.1109065

United Nations Division for Sustainable Development. (1993). Agenda 21: Earth Summit- The United Nations programme of action from Rio. New York, NY: United Nations Department of Public Information.

United Nations Educational, Scientific and Cultural Organization (2005). Guidelines and recommendations for reorienting teacher education to address sustainability (Technical Paper No. 2). Paris, France.

UNPF (United Nations Population Fund) (2001). The state of the world population 2001-FootPrints and Milestones: population and Environmental Change. UNFPA. New York.

Wakefield, J. (2003). Teaching sustainability. Environmental Health Perspectives, $111(5), 270$.

Wensing, E.J., \& Torre, C. (2009). The ecology of education: Knowledge systems for Sustainable development and sustainability. Journal of Teacher Education for Sustainability, 11(1), 3-17. doi: 10.2478/v10099-009-0028-z.

World Commission on Environment and Development (1987). Our common future. Oxford, UK: Oxford University.

Yıldırım, A., \& Şimşek, H. (2016). Sosyal bilimlerde nitel araştırma yöntemleri. Seçkin Yayıncilik.

Zheng, H. (2009). A review of research on EFL pre-service teachers' beliefs and practices. Journal of Cambridge Studies, 4(1), 73-81. 
This is an Open Access article distributed under the terms of the Creative CommonsAttributionNonCommercial-ShareAlike 4.0 International (CC BY-NC-SA 4.0). For further information, you can refer to https://creativecommons.org/licenses/by-nc-sa/4.0/ 